\title{
Alterações patológicas do sistema genital de cutias (Dasyprocta aguti Linnaeus, 1758) fêmeas criadas em cativeiro ${ }^{1}$
}

\author{
Jael S. Batista ${ }^{2 *}$, Carlos I.A. Freitas ${ }^{2}$, Francisco S. Brilhante², Geysa A. Viana², Roberio \\ G. Olinda ${ }^{3}$, Tânia V. Cavalcante ${ }^{4}$, Kaliane A.R. de Paiva² e Moacir F. de Oliveira ${ }^{2}$
}

\begin{abstract}
Batista J.S., Freitas C.I.A., Brilhante F.S., Viana G.A., Olinda R.G., Cavalcante T.V., Paiva K.A.R. \& Oliveira M.F. 2016. [Pathological changes of the genital system of agoutis (Dasyprocta aguti Linnaeus, 1758) females bred in captivity.] Alterações patológicas do sistema genital de cutias (Dasyprocta aguti Linnaeus, 1758) fêmeas criadas em cativeiro. Pesquisa Veterinária Brasileira 36(7):634-641. Departamento de Ciências Animais, Universidade Federal Rural do Semi-Árido, Avenida Francisco Mota, Presidente Costa e Silva, Mossoró, RN 59625-900, Brazil. E-mail: jaelsoares@hotmail.com

This paper presents seven distinct reports diseases with reproductive origins that are not yet described in females agoutis (Dasyprocta aguti Linnaeus, 1758), affecting fertility or resulted in the animal's death. The nature, location and frequency of macroscopic and histological pathological changes of the organs that compose the reproductive system of female agoutis, created under conditions of captivity in the semiarid region of Brazil, are described in this article. Were evaluated by pathological examination of the reproductive tract of thirty-nine naturally dead agoutis and sent to the Veterinary Pathology Laboratory in February 2010 to May 2015. From these, it was found pathological alterations in the reproductive system of $10(25.6 \%)$. A total of 13 abnormalities were observed, and in some animals had the coexistence of more than one alteration. Thus, the pathological changes were: endometritis $(n=4,30.8 \%)$, pyometra $(n=3 ; 23 \%)$, retained placenta $(n=2 ; 15.4 \%)$, fetal maceration $(n=1,7.7 \%)$, fetal mummification $(n=1,7.7 \%)$, dystocia $(n=1,7.7 \%)$ and afuncionais ovary $(\mathrm{n}=1,7.7 \%)$.
\end{abstract}

INDEX TERMS: Pathology of reproduction, pathological diagnosis, wild animal, Dasyprocta aguti.

RESUMO.- Este artigo apresenta relatos de sete distintas patologias de origem reprodutiva ainda não descritas em cutias (Dasyprocta aguti Linnaeus, 1758) fêmeas, que afetaram a fertilidade ou resultaram na morte do animal. Descreveu-se a natureza, a localização e a frequência das alterações patológicas macroscópicas e histológicas dos órgãos que compõem o sistema reprodutivo de cutias fêmeas, criadas sob condições de cativeiro no semiárido do Brasil. Foram

\footnotetext{
${ }^{1}$ Recebido em 3 de agosto de 2015.

Aceito para publicação em 14 de abril de 2016.

${ }^{2}$ Departamento de Ciências Animais, Universidade Federal Rural do SemiÁrido (UFERSA), Av. Francisco Mota, Presidente Costa e Silva, Mossoró, RN 59625-900, Brasil. *Autor para correspondência: jaelsoares@hotmail.com

${ }^{3}$ Departamento de Patologia Animal, Universidade Federal de Campina Grande (UFCG), Rua Aprígio Veloso 882, Universitário, Campina Grande, PB 58429-900, Brasil.

${ }^{4}$ Departamento de Clínica e Cirurgia Veterinária, Universidade Federal do Piauí (UFPI), Campus Universitário Ministro Petrônio Portella, Ininga, Teresina, PI 64049-550, Brasil.
}

avaliados através do exame anatomopatológico o aparelho reprodutivo de trinta e nove cutias mortas naturalmente e encaminhadas ao Laboratório de Patologia Veterinária, no período de fevereiro de 2010 a maio de 2015. Destas, constatou-se alterações patológicas no sistema reprodutivo de $10(25,6 \%)$. No total, 13 alterações foram observadas, sendo que, em alguns animais haviam a coexistência de mais de uma alteração. Assim, as alterações patológicas encontradas foram: endometrite $(n=4 ; 30,8 \%)$, piometra $(n=3$; $23 \%)$, retenção de placenta ( $\mathrm{n}=2 ; 15,4 \%)$, maceração fetal ( $\mathrm{n}=1 ; 7,7 \%)$, mumificação fetal $(\mathrm{n}=1 ; 7,7 \%)$, parto distócico $(\mathrm{n}=1 ; 7,7 \%)$ e ovários afuncionais $(\mathrm{n}=1 ; 7,7 \%)$.

TERMOS DE INDEXAÇÃO: Patologia da reprodução, diagnóstico anatomopatológico, animal silvestre, agouti, Dasyprocta aguti.

\section{INTRODUÇÃO}

A criação em cativeiro de animais silvestres apresenta perspectivas interessantes do ponto de vista socioeconô- 
mico e ambiental, no qual a potencialidade reprodutiva observada em algumas espécies é um elemento favorável, sendo necessário selecionar espécies que apresentem bom desempenho reprodutivo (Martinez et al. 2013, Barros et al. 2015). Neste contexto, patologias no sistema reprodutivo desses animais podem surgir e causar infertilidade, redução do peso da prole ou aumento na taxa de natimortos (Nakade et al. 2015). Assim, o conhecimento sobre as doenças que acometem o sistema reprodutor dos animais silvestres pode contribuir para o controle das desordens reprodutivas, bem como, auxiliar na implementação de programas de manejo reprodutivo, através da seleção de animais férteis para o acasalamento, criopreservação de gametas e inseminação artificial (Ohashi et al. 2012).

0 exame anatomopatológico dos órgãos do sistema reprodutivo mostra-se como uma ferramenta prática e eficiente para as identificações dos reais motivos que desencadeiam os transtornos reprodutivos, já que permite uma análise direta e detalhada dos aspectos macro e microscópicos das lesões (Azawi et al. 2010).

Dentre os animais da fauna silvestre brasileira, a cutia (Dasyprocta sp.) é um mamífero roedor neotropical que apresenta alta rusticidade, boa prolificidade, precocidade, além de satisfatória fertilidade em cativeiro, o que pode viabilizar sua exploração econômica e implementação de programas de repovoamento (Vieira 2009, Figueira et al. 2014). Apesar destes fatos, sabe-se que a manutenção do animal em condições de cativeiro pode produzir variações reprodutivas devido a diferentes fatores, tais como, o estresse do próprio cativeiro e à dieta, entre outros (Quesnel et al. 1998). Dessa forma, o presente trabalho tem como objetivos verificar a natureza, a localização e a frequência das alterações patológicas macroscópicas e histológicas dos órgãos que compõem o sistema genital de cutias fêmeas criadas em cativeiro.

\section{MATERIAL E MÉTODOS}

Foram avaliadas no presente estudo 39 cutias (Dasyprocta aguti Linnaeus, 1758) adultas, oriundas do Centro de Multiplicação de Animais Silvestres (CEMAS) da Universidade Federal Rural do Semi-Árido (UFERSA), localizada no município de Mossoró, Estado do Rio Grande do Norte, registrado como criatório científico junto ao Instituto Brasileiro de Manejo e Recurso Naturais Renováveis (IBAMA) sob o número 14.789.12.

Os animais foram mantidos em recintos telados $(2,5 \times 2,5 \mathrm{~m})$ e separados em categorias de acordo com o sexo e faixa etária para a realização do manejo reprodutivo e sanitário. A alimentação fornecida era constituída de milho em grão, frutas, vegetais verdes, ração comercial para coelho, suplementada com complexo vitamínico e mineral na forma farelada e água ad libidum.

As cutias utilizadas tiveram morte natural e foram encaminhadas ao Laboratório de Patologia Veterinária, no período compreendido entre fevereiro de 2010 a maio de 2015. Nos animais diagnosticados com alterações patológicas dos órgãos genitais, realizou-se um levantamento dos dados nas fichas de identificação individual no plantel referentes ao histórico reprodutivo, com o intuito de saber a idade ao primeiro parto, número de crias por parto, ocorrência de abortamento e natimortalidade, além dos sinais clínicos associados a distúrbios da gestação, parto e puerpério, bem como, tipo de tratamento realizado para estas enfermidades.
O sistema reprodutivo completo foi removido da carcaça, dissecado, avaliado macroscopicamente e fotografados, quando apresentavam achados significativos. Fragmentos de ovários, tuba uterina, útero, cérvix, vagina e placenta foram coletados e fixados em formol 10\%, processados de forma rotineira para histologia, incluídos em parafina, cortados a $5 \mu \mathrm{m}$ de espessura e corados pela hematoxilina-eosina (HE) (Prophet et al. 1992).

Nos órgãos com evidencias de infecção e presença de exsudatos purulentos, foram colhidas alíquotas do conteúdo através de swabs para a realização do isolamento e identificação do agente etiológico. As amostras foram semeadas em Ágar sangue de carneiro desfibrinado (5\%), seguindo-se à incubação em estufa bacteriológica a uma temperatura de $37^{\circ} \mathrm{C}$ por 48 horas em aerobiose (Olinda et al. 2010). A classificação foi realizada de acordo com as características macroscópicas do cultivo e morfotintoriais (método de coloração de Gram) e o perfil bioquímico (MacFaddin 2000, Murray et al. 2003).

Os dados relacionados as alterações patológicas do sistema reprodutivo de cutias foram expressos em frequência simples e porcentagem através do programa estatístico SPSS (Armonk, NY: IBM Corp.) versão 22.0.

Declaramos para os devidos fins que o trabalho intitulado Alterações patológicas do sistema genital de cutias (Dasyprocta aguti Linnaeus, 1758) fêmeas criados em cativeiro, submetido junto ao corpo editorial do periódico Pesquisa Veterinária Brasileira, foi oriundo de casos de óbito natural em cutias criadas em cativeiro no Centro de Multiplicação de Animais Silvestres (CEMAS). Portanto, os procedimentos de necropsia não desrespeitam os princípios éticos preconizados pelo Colégio Brasileiro de Experimentação Animal (COBEA) e nem os de biossegurança, pois não foram realizados ensaios de natureza experimental. Assumimos a responsabilidade pelo seu conteúdo, colocando-nos à disposição para colaborar, no que for necessário, para identificação de fontes e informações gerais que nortearam a construção do presente manuscrito.

\section{RESULTADOS}

Do total de 39 cutias fêmeas analisadas, foram observadas lesões no sistema reprodutivo de $10(25,6 \%)$ animais. A coexistência de mais de um tipo de alteração em um mesmo animal é o motivo pelo qual o número de diagnósticos ter atingido o total de 13 (Quadro 1). Dos órgãos em que foram observadas alterações, o útero foi o que apresentou maior frequência, sendo os processos inflamatórios os mais diagnosticados.

A endometrite foi diagnosticada em $4(30,8 \%)$ animais, nos quais foram constatados, após análise de cada ficha de identificação individual, registros que no primeiro caso havia abortamento e retenção de placenta, no segundo ausência de parições por um período de um ano, no terceiro retenção de placenta e no quarto feto macerado.

Quanto ao aspecto macroscópico do útero, os animais com retenção de placenta apresentaram mucosa uterina congesta, hemorrágica e edemaciada. Enquanto que no animal com feto macerado, o endométrio apresentou-se hiperêmico e espessado, recoberto com exsudato fibrinopurulento (Fig.1). Não foram observadas alterações macroscópicas no útero da cutia que abortou e que apresentava histórico de infertilidade.

Nos animais com histórico de retenção de placenta ou feto macerado observou-se endometrite aguda difusa caracterizada por infiltrado inflamatório de células poli- 
Quadro 1. Número de animais e frequência (\%) das alterações patológicas encontradas no sistema reprodutivo de 10 cutias (Dasyprocta aguti), criadas em cativeiro no município de Mossoró, Rio Grande do Norte, no período de fevereiro de 2010 a maio de 2015

\begin{tabular}{|c|c|c|c|c|c|c|}
\hline \multirow[t]{2}{*}{ Animal } & \multicolumn{6}{|c|}{ Patologias Reprodutivas } \\
\hline & Endometrite Piometra & $\begin{array}{l}\text { Retenção } \\
\text { Placenta }\end{array}$ & $\begin{array}{c}\text { Maceração } \\
\text { fetal }\end{array}$ & $\begin{array}{c}\text { Mumificação } \\
\text { fetal }\end{array}$ & $\begin{array}{c}\text { Parto } \\
\text { Distócico }\end{array}$ & $\begin{array}{c}\text { Ovários } \\
\text { Afuncionais }\end{array}$ \\
\hline
\end{tabular}

\begin{tabular}{|c|c|c|c|c|c|c|c|}
\hline & & & & & & & \\
\hline 1 & 1 & - & 1 & - & - & - & - \\
\hline 2 & 1 & - & 1 & - & - & - & - \\
\hline 3 & 1 & - & - & 1 & - & - & - \\
\hline 4 & 1 & - & - & - & - & - & - \\
\hline 5 & - & 1 & - & - & - & - & - \\
\hline 6 & - & 1 & - & - & - & - & - \\
\hline 7 & - & 1 & - & - & - & - & - \\
\hline 8 & - & - & - & - & - & 1 & - \\
\hline 9 & - & - & - & - & - & - & 1 \\
\hline 10 & - & - & - & - & 1 & - & - \\
\hline Total & 4 & 3 & 2 & 1 & 1 & 1 & 1 \\
\hline Frequência \% & $30,8 \%$ & $23 \%$ & $15,4 \%$ & $7,7 \%$ & $7,7 \%$ & $7,7 \%$ & $7,7 \%$ \\
\hline
\end{tabular}

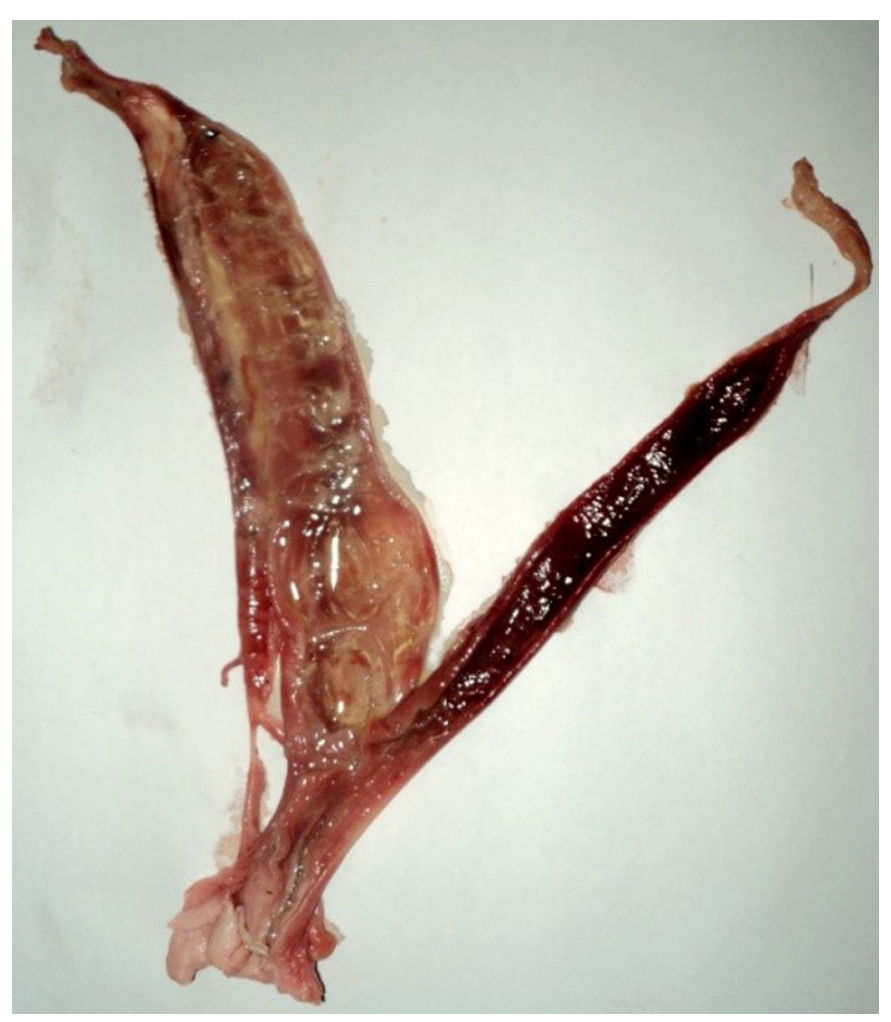

Fig.1. Aspecto macroscópico da endometrite em cutia (Dasyprocta aguti) criada em cativeiro. A mucosa uterina é hiperêmica, espessada e recoberta com exsudato fibrinopurulento.

morfonucleares no endométrio, áreas focais de necrose do epitélio e presença de glândulas distendidas, com acúmulo de exsudato no lúmen (Fig.2). Nas cutias com histórico de abortamento e infertilidade, a endometrite foi crônica caracterizada por infiltrado linfoplasmocitário multifocal no interstício e ao redor dos vasos, além de discreta fibrose periglandular.

A piometra foi diagnosticada macroscopicamente em 3 (23\%) cutias. Durante a necropsia observou-se que os animais apresentavam os cornos uterinos distendidos, com presença em seu interior de exsudato purulento viscoso de coloração branco-amarelada, além da mucosa uterina, es-

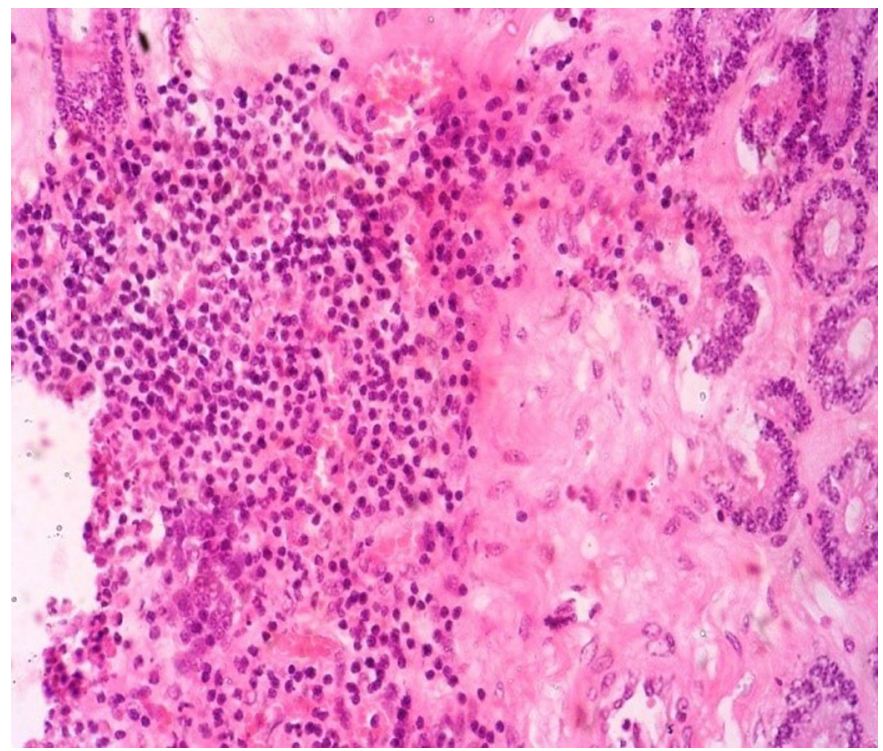

Fig.2. Aspecto histológico da endometrite em cutia (Dasyprocta aguti) criada em cativeiro. Infiltrado inflamatório de células polimorfonucleares no endométrio e presença de glândulas distendidas. HE, obj.20x.

pessada e hiperêmica (Fig.3). Em todos os animais foi possível observar presença de corpo lúteo em pelo menos um dos ovários. No exame histológico observou-se no lúmen uterino grande quantidade de células polimorfonucleares, detritos celulares e filamentos de fibrina. Foi possível ainda, confirmar a ocorrência de corpos lúteos funcionais caracterizados pela presença de células luteínicas hiperplásicas e hipertrofiadas, que ocupavam grande parte do tecido ovariano. $\mathrm{Na}$ análise microbiológica do conteúdo uterino purulento, foi identificada a presença de Escherichia coli em 2 cutias e Staphylococcus aureus em outra.

A retenção de placenta ocorreu a partir de uma complicação pós-parto diagnosticada em $2(15,4 \%)$ cutias, sendo que em um animal a retenção foi parcial e em outro total. 0 primeiro animal apresentou após o parto, sinais de inquietação, cólica, esforço expulsivo recorrente e presença de envoltórios pendentes na vulva (Fig.4). Houve agravamen- 
to do quadro clínico e após apresentar apatia, fraqueza e secreção vulvar viscosa enegrecida, a cutia morreu no terceiro dia sem expulsão das membranas fetais. No segundo animal, a retenção de placenta foi diagnosticada apenas durante a necropsia, pois a cutia havia sido encontrada morta no recinto dois dias após o parto. No referido animal foi observado distensão acentuada do corno uterino direito e presença no seu interior da placenta autolisada (Fig.5).

Diagnosticou-se $1(7,7 \%)$ caso de maceração fetal, ocorrido em uma cutia multípara, que havia sido colocada nas baias de reprodução. Contudo, por ocasião da transferência dos animais para baia de parição, constatou-se que a cutia não apresentava desenvolvimento abdominal compatível
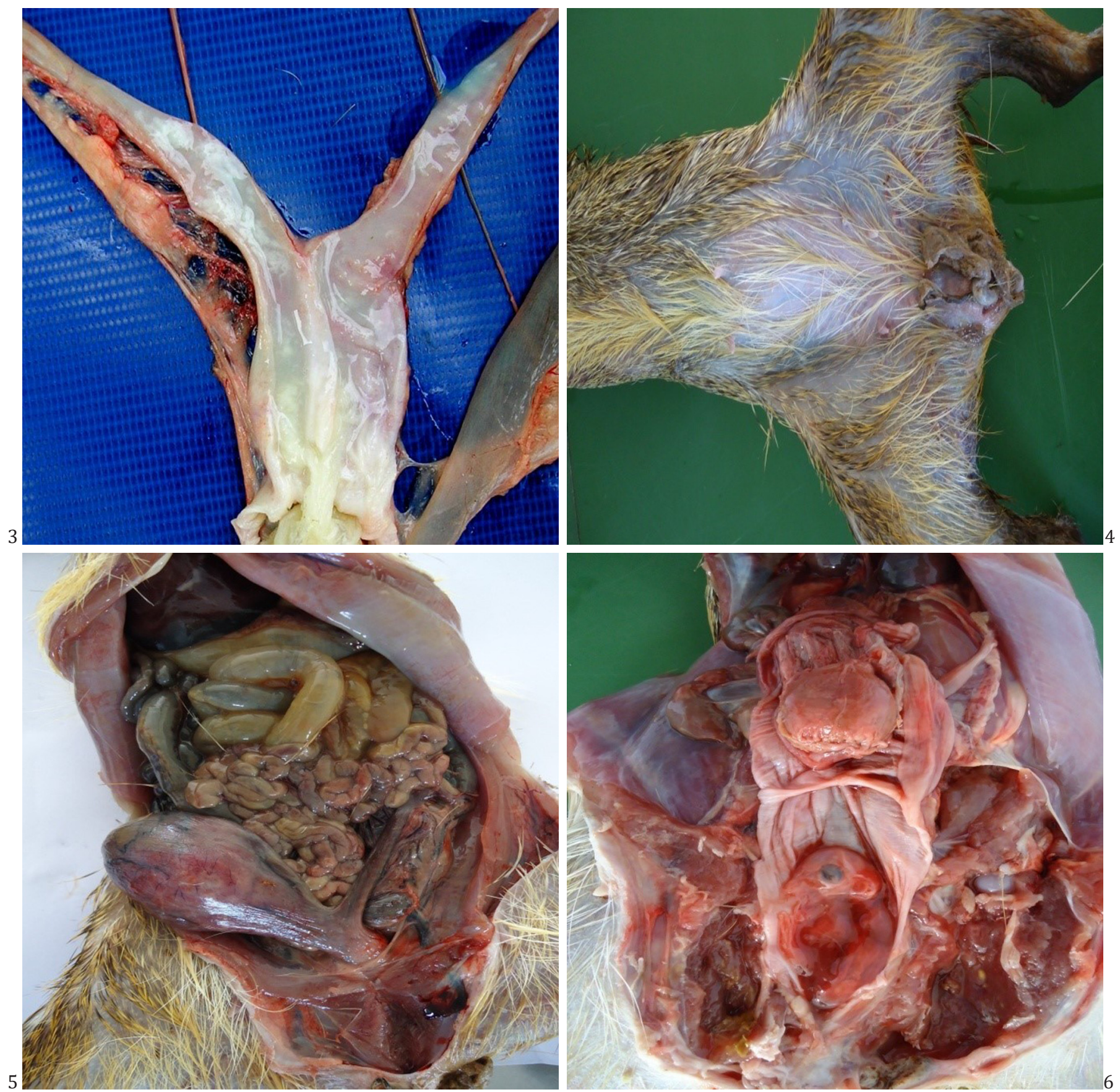

Fig.3. Aspecto macroscópico da piometra em cutia (Dasyprocta

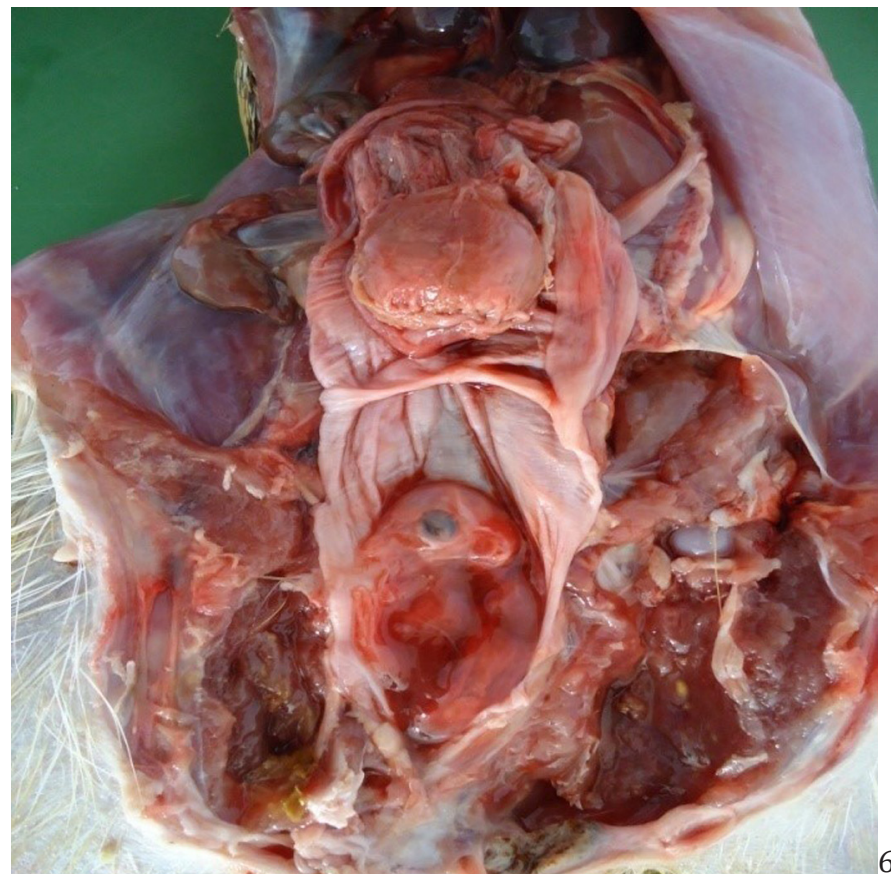

Fig.4. Aspecto macroscópico da retenção parcial de placenta em aguti) criada em cativeiro, após a abertura do corpo e cornos uterinos. Presença de exsudato purulento viscoso de coloração branco-amarelado.

Fig.5. Aspecto macroscópico da retenção total de placenta em cutia (Dasyprocta aguti) criada em cativeiro. Corno uterino direito distendido, contendo em seu interior, placenta retida. cutia (Dasyprocta aguti) criada em cativeiro. Exposição de parte da placenta pela vulva (seta).

Fig.6. Aspecto macroscópico da maceração fetal em cutia (Dasyprocta aguti) criada em cativeiro. Presença de um feto no interior do útero com tecidos liquefeitos e ossos (seta). 
com gestação e apresentava-se apática, desidratada e com perda de peso. No exame físico, percebeu-se corrimento vaginal mucopurulento. Foi estabelecido o tratamento com enrofloxacina $5 \mathrm{mg} / \mathrm{kg}$, via intramuscular, por sete dias, mas o animal não respondeu ao tratamento, decorrendo o óbito. Durante a necropsia constatou-se, em meio ao exsudato mucopurulento, presença do crânio de um feto, além de ossos dos membros que se separavam facilmente nas articulações quando manipulados e resquícios de tecidos fetais liquefeitos, estabelecendo assim, o diagnóstico de maceração fetal (Fig.6).

A mumificação fetal foi diagnosticada no exame necroscópico de $1(7,7 \%)$ cutia, no qual foi constatada na ficha de identificação individual, que o animal havia acasalado há cinco meses e não apresentava sintomas de prenhes. No referido animal, foi observado na necropsia que o útero continha a presença de um feto mumificado, desidratado, de coloração marrom escuro, sem odor, sem exsudação e com cavidade ocular vazia (Fig.7).

Foi diagnosticado um caso de distocia em $1(7,7 \%)$ cutia durante a inspeção diária na baia da maternidade, pois apresentava muitas contrações abdominais e a cabeça do feto estava exposta para fora da vulva. No exame físico constatou-se que o feto estava morto, possivelmente devido à pouca dilatação da cérvix. Por esta razão, administrou-se estrógeno intramuscular $(0,25 \mathrm{mg} / \mathrm{kg})$, contudo não ocorreu o parto e oito horas após a aplicação do medicamento o animal morreu. Na necropsia, observou-se presença de um feto grande, enfisematoso que se encontrava em apresentação longitudinal anterior, posição ventral, com o ventre voltado para o dorso da mãe (Fig.8).

Diagnosticou-se um caso de ovários afuncionais em

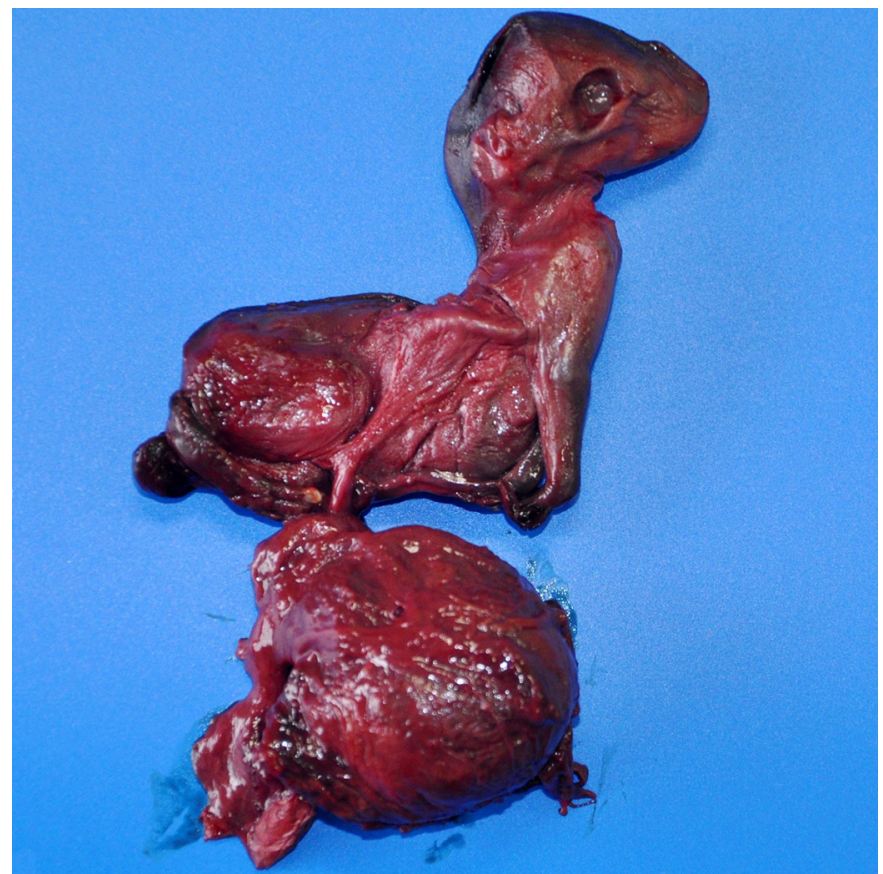

Fig.7. Aspecto macroscópico da mumificação fetal em cutia (Dasyprocta aguti) criada em cativeiro. Presença de um feto desidratado, de coloração marrom escuro e com cavidade ocular vazia.

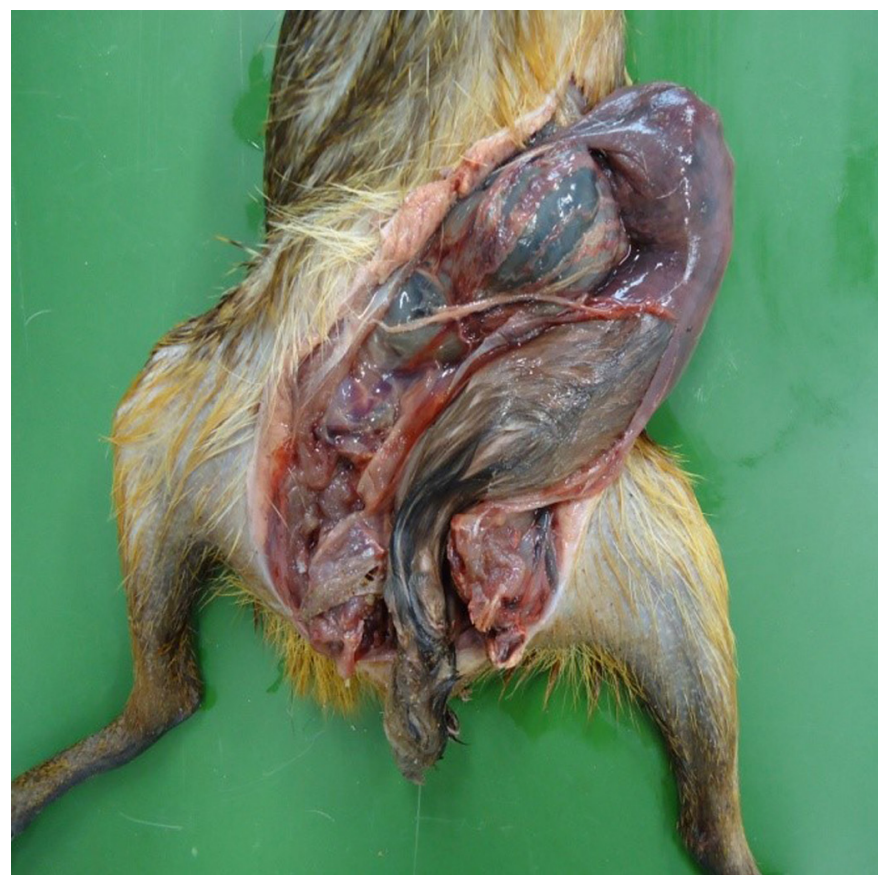

Fig.8. Aspecto macroscópico da distocia fetal em cutia (Dasyprocta aguti) criada em cativeiro. Disposição fetal anormal, com apresentação longitudinal anterior, posição ventral (ventre do feto voltado para o dorso da mãe) e cabeça exposta para fora da vulva.

$1(7,7 \%)$ cutia de dois anos, descartada do plantel após avaliação dos dados reprodutivos indicarem que o animal apresentava histórico de uma parição apenas, mesmo tendo sido colocada com frequência nas baias de reprodução junto aos machos. Macroscopicamente, os ovários apresentaram-se reduzidos de tamanho, com formato arredondado, superfície lisa e ausência de folículos ovarianos ou corpos lúteos. No exame histológico os ovários apresentaram presença de folículos imaturos (primordiais e primários) degenerados com núcleo picnótico, retração oocitária e desorganização das camadas de células da granulosa. Observaram-se ainda, aumento do tecido conjuntivo da região cortical e ausência de corpo lúteo.

\section{DISCUSSÃO}

As doenças do sistema reprodutor são frequentes na medicina veterinária, tanto nas fêmeas quanto nos machos das diferentes espécies domésticas. Sabe-se que o diagnóstico das enfermidades reprodutivas em animais silvestres é, muitas vezes, uma tarefa difícil. Assim, o exame anatomopatológico é especialmente útil, uma vez que, em muitas ocasiões, manifestações clínicas de enfermidades nestas espécies não são características como em animais domésticos. Nesses casos, a necropsia tem fundamental importância para chegar ao diagnóstico correto. A utilização cada vez mais frequente do exame necroscópico vem demonstrando que doenças antes consideradas raras, ocorrem com relativa frequência em animais silvestres criados em cativeiro ou em vida livre (Batista et al. 2010).

Neste estudo foram descritos os aspectos anatomopatológicos de sete distintas patologias da esfera reprodutiva, 
que afetaram a fertilidade ou resultaram na morte do animal, ainda não descritas em cutias fêmeas. Entre as alterações patológicas do sistema reprodutivo de cutias que mais se destacaram, foram localizadas no útero, sendo a endometrite observada em maior frequência.

A endometrite é o processo inflamatório mais frequente no útero de diversas fêmeas domésticas que interfere negativamente na eficiência reprodutiva, aumentando a ocorrência de repetição de cio, intervalos entre partos e a taxa de refugo (Wagener et al. 2014, Pothmann et al. 2015, Xu et al. 2015). Neste estudo, as alterações encontradas como fator predisponente à endometrite foram retenção de placenta, abortamento e maceração fetal. A relação entre as alterações patológicas parece claras, uma vez que, segundo dados da literatura a endometrite frequentemente ocorre como sequela da distocia, retenção de placenta, abortamento, prolapso uterino e, as lesões traumáticas que afetam os mecanismos de defesa e imunossenescência expõem o animal às infecções (Boralli \& Zappa 2012). Outro fator que deve ser ressaltado é a ocorrência de endometrite crônica em uma cutia infértil, diagnosticada no exame histológico pela presença de infiltrado linfoplasmocitário multifocal no interstício, além de fibrose periglandular. Esses achados apontam que, semelhante a outras espécies, a endometrite pode ocorrer na forma subclínica e deve ser considerada como possível fator associado à infertilidade em cutias.

Durante exame post-mortem, três casos de piometra foram diagnosticados em cutias que não apresentaram secreção vaginal, sendo dessa forma a piometra classificada como fechada. 0 tipo de piometra observado pode ter contribuído para o curso fatal da enfermidade. A piometra fechada apresenta prognóstico ruim, com elevadas taxas de letalidade e frequentemente resulta em septicemia, pois acumula grande quantidade de pus dentro da luz uterina, associada à liberação de endotoxinas que provocam alterações sistêmicas, resultando quase sempre na morte do animal (Evangelista et al. 2010).

Em trabalho de avaliação das doenças de chinchilas (Chinchilla lanígera), diagnosticados através de estudos dos casos de necropsia realizados no Laboratório de Patologia Veterinária da Universidade Federal de Santa Maria (UFSM), Lucena et al. (2012) verificaram que 25,7\%, 52 de 202 casos, foram doenças inflamatórias, dentre estas por quatro casos de piometra e dois de endometrite.

A presença de Escherichia coli isolada do exsudato purulento intrauterino em duas cutias está de acordo com dados da literatura, os quais relatam-se grande afinidade dessa bactéria pelo endométrio e miométrio, sendo o microrganismo mais comumente isolado de animais doméstico com piometra (Chan et al. 2000). Staphylococcus aureus é outro microrganismo descrito na literatura frequentemente associado a infecções uterinas (Azawi et al. 2010), o qual foi também observado em uma cutia. $\mathrm{O}$ isolamento de E. coli e $S$. aureus no conteúdo uterino purulento de cutias com piometra é um fato inédito e evidencia a participação desses microrganismos como agente etiológico de distúrbios reprodutivos nesta espécie.

A microbiota do útero e da vagina em cutias nulíparas e não nulíparas saudáveis foi avaliada por Martins et al.
(2012). Os autores constataram que cutias nulíparas e não nulíparas apresentaram colonização da vagina por bactérias e leveduras de diferentes gêneros, diferentemente do observado no útero, órgão que apresentou colonização em apenas um animal não nulíparo, no qual foi isolado Proteus sp.

A via de infecção e os fatores predisponentes para a ocorrência da piometra dos casos acima relatados não puderam ser elucidados, mas sabe-se que a contaminação bacteriana do útero ocorre geralmente por via ascendente, presumivelmente da microbiota vaginal, resultando no desenvolvimento de endometrite ou piometra (Kempisty et al. 2013).

Quanto aos fatores predisponentes para a ocorrência da piometra, têm sido amplamente mencionados, que esta doença é um distúrbio que ocorre geralmente na fase do diestro, sendo mediada por alterações hormonais e uma reposta exagerada ao estímulo da progesterona, que estimulam a secreção das glândulas endometriais, as quais sofrem hiperplasia e hipertrofia, além de diminuir a contratilidade miometral, criando um ambiente intra-uterino que predispõe ao crescimento bacteriano (Asa et al. 2014). Os resultados referentes à histopatologia dos ovários observados nas cutias com piometra, foram compatíveis com fase progesterônica, ou seja, os ovários continham corpos lúteos funcionais, fato que permite sugerir que a progesterona pode ter contribuído na patogênese da piometra no presente estudo.

A retenção de placenta, complicação pós-parto caracterizada pela ausência de expulsão das membranas fetais foi observada em duas $(15,4 \%)$ cutias. Embora estudos de caracterização morfológica da placenta de animais silvestres venham despertado interesse nas ultimas décadas, poucos estudos foram publicados sobre as enfermidades placentárias. Assim, na maioria das espécies silvestres, é desconhecido o tempo normal de expulsão da placenta após o término do parto. Sabe-se que na tentativa de ocultar o nascimento de uma cria vulnerável perante os predadores, com muita frequência, a expulsão da placenta nos animais silvestres ocorre em um intervalo muito curto, nesta ocasião é comum a placentofagia pela parturiente (Kristal et al. 2012). As cutias com retenção de placenta no presente estudo apresentaram sinais clínicos similares a outras espécies domésticas com o mesmo problema: inquietação pós-parto, evidências de cólica, esforços expulsivos recorrentes, presença de envoltórios pendentes na vulva e a eliminação de secreção vulvar. Quanto ao tempo de expulsão da placenta, a retenção perdurou por três dias em uma cutia, quando então ocorreu a morte do animal.

Não foi possível identificar a causa de retenção de placenta nas cutias do presente estudo. Nas espécies domésticas, a retenção placentária ocorre devido à inércia uterina ou a inflamação da placenta, o que ocasiona falha no descolamento das vilosidades fetais. Fato associado a alguns fatores predisponentes como: estresse, falhas de manejo, doenças bacterianas, metabólicas, deficiência de vitaminas e minerais, distensão excessiva do útero, distúrbios hormonais, hereditariedade, distocias, abortamentos e nascimentos prematuros. (Benedictus et al. 2012, Benedictus et al. 2013, Cui et al. 2014). 
A maceração e a mumificação fetal foram outras alterações patológicas observadas no útero, ainda não relatadas em cutias. De acordo com Montanha et al. (2012) a maceração fetal é um indício de que a morte fetal ocorreu e o feto não foi abortado, seguido da contaminação do ambiente uterino por infecção ascendente através da cérvix e vagina materna, causando destruição do feto retido na cavidade uterina e, em algumas situações mais graves, septicemia. Ao contrário da maceração, o requisito básico para que haja mumificação é a ausência de contaminação bacteriana na cavidade uterina. Os líquidos fetais são reabsorvidos e as membranas fetais aderem-se ao feto morto desidratado (Nascimento \& Santos 2003).

0 parto distócico também foi observado em uma cutia que apresentava contrações abdominais e dificuldade em expulsar um feto que se encontrava com a cabeça exposta para fora da vulva. Nos mamíferos domésticos a disposição fetal normal no momento de parto fisiológico ou eutócico deve ser em apresentação longitudinal anterior, posição superior e atitude estendida (Andolfato \& Delfiol 2014). 0 feto encontrava-se em apresentação longitudinal anterior, posição ventral com o ventre voltado para o dorso da mãe. Assim, a distocia observada pode ser classificada como de origem fetal, relacionada à estática ou má postura fetal, a qual resultou no óbito da mãe e do feto. De forma semelhante às demais patologias do trato reprodutivo de cutias observadas no presente estudo, poucos relatos estão disponíveis sobre a ocorrência de parto distócico em mamíferos silvestres. No entanto, merece destaque o trabalho realizado por Batista et al. (2010), que relatam o primeiro caso do envolvimento de distocia como causa de óbito em cutias no período periparturiente. Os autores observaram $2(6,24 \%)$ casos de parto distócico diagnosticados em 32 cutias criadas cativeiro e submetidas à necropsia. Consideraram ainda a distocia como importante diagnóstico dentre as enfermidades observadas no estudo.

No tocante as alterações patológicas observadas nos ovários, baseou-se no histórico clínico reprodutivo para o diagnóstico de ovários afuncionais, onde foi constatado que animal permanecia por um longo período sem parições, bem como nos achados de necropsia e na histopatologia. Os achados anatomopatológicos macroscópicos e histológicos observados no presente estudo, assemelham-se às descritas por Nascimento \& Santos (2003) que caracterizam essa condição quando animais em anestro apresentam ovários pequenos de consistência firme, superfície lisa e sem evidencias histológicas de folículos e corpo lúteo funcional.

É importante diferenciar ovários afuncionais da hipoplasia ovariana, já que a primeira alteração ocorre em animais adultos, é de caráter adquirida, reversível e tratável e a segunda tem origem hereditária e, portanto, irreversível (Rolim Filho et al. 2011, Ticianelli et al. 2011, Ohashi et al. 2012). Também, na hipoplasia ovariana, os animais afetados são estéreis e geralmente apresentam tratos reprodutivos infantis, fato não observado na cutia em questão, pois já havia reproduzido e apresentava os órgãos que compõem o sistema reprodutivo com aspecto morfológico normal.

\section{CONCLUSÕES}

O exame anatomopatológico dos órgãos que compõem o sistema genital de cutias fêmeas criadas em cativeiro, possibilitou o diagnóstico de patologias reprodutivas de natureza inflamatória (endometrite e piometra), do útero gestante (feto macerado e mumificado), do parto (distocia), do puerpério (retenção de placenta) e regressivas (ovários afuncionais), ainda não descritos para a espécie.

Estas doenças afetaram a fertilidade e/ou resultaram na morte do animal.

\section{REFERÊNCIAS}

Andolfato G.M. \& Delfiol D.J.Z. 2014. Principais causas de distocia em vacas e técnicas para correção: revisão de literatura. Rev. Cient. Med. Vet. 12 (22):1-16.

Asa C.S., Bauman K.L., Devery S., Zordan M., Camilo G.R., Boutelle S. \& Moresco A. 2014. Factors associated with uterine endometrial hyperplasia and pyometra in wild canids: implications for fertility. Zoo Biol. 33 (1):8-19.

Azawi O.I., Al-Abidy H.F. \& Ali A.J. 2010. Pathological and bacteriological studies of hydrosalpinx in buffaloes. Reprod. Dom. Anim. 45:416-420.

Barros F.F.P.C., Teixeira P.P.M., Uscategui R.A.R., Padilha L.C., Kawanami A.E., Lima M.R., Almeida V.T., Mariano R.S.G., Nociti R.P., Machado M.R.F. \& Vicente W.R.R. 2015. Aspectos reprodutivos, endocrinológicos e de produção in vitro em pacas (Cuniculus paca Linnaeus, 1766). Invest. 14 (1):1-6.

Batista J.S., Olinda R.G., Silva T.M.F., Rodrigues C.M.F., Oliveira A.F., Queiroz S.A.C., Morais S.R.L. \& Oliveira M.F. 2010. Enfermidades de cutias (Dasyprocta aguti) criadas em cativeiro diagnosticadas pelo exame anatomopatológico. Pesq. Vet. Bras. 30(6):497-502.

Benedictus L., Thomas A.J., Jorritsma R., Davies C.J. \& Koets A.P. 2012. Two-Way Calf to Dam Major Histocompatibility Class I Compatibility Increases Risk for Retained Placenta in Cattle. Am. J. Reprod. Immunol. 67:224-230.

Benedictus L., Koets A.P., Kuijpers F.H.J., Joosten I., Eldik P.V. \& Heuven H.C.M. 2013. Heritable and non-heritable genetic effects on retained placenta in Meuse-Rhine-Yssel cattle. Anim. Reprod. Sci. 137:1-7.

Boralli I.C. \& Zappa V. 2012. Endometrite em bovinos: revisão de literatura. Revta Cient. Eletr. Med. Vet. 9(18):1-28.

Chan L.Y., Yu V.S., Ho L.C., Lok Y.H. \& Hui S.K. 2000. Spontaneous uterine perforation of pyometra. A report of three cases. J. Reprod. Med. 45 (10):857-860.

Cui D., Li J., Wang X., Xie J., Zhang K., Wang X., Zhang J., Wang L., Qin Z. \& Yang Z. 2014. Efficacy of herbal tincture as treatment option for retained placenta in dairy cows. Anim. Reprod. Sci. 145:23-28.

Evangelista L.S.M., Quessada A.M., Alves R.P.A., Lopes R.R.F.B. \& Gonçalves L.M.F. 2010. Função renal em cadelas com piometra antes e após ovariosalpingohisterectomia. Acta Vet. Brasilica 4(3):153-161.

Figueira L., Zucaratto R., Pires A.S., Cid B. \& Fernandez F.A.Z. 2014. Carrion consumption by Dasyprocta leporina (Rodentia: Dasyproctidae) and a review of meat use by agoutis. Braz. J. Biol. 74(3):585-587.

Kempisty B., Bukowska D., Wozna M., Piotrowska H., Jackowska M., Zuraw A., Ciesiolka S., Antosik P., Maryniak H., Ociepa E., Porowski S., Brussow K.P., Jaskowski J.M. \& Nowicki M. 2013. Endometritis and pyometra in bitches: a review. Vet. Med. 58(6):289-297.

Kristal M.B., Dipirro J.M. \& Thompson A.C. 2012. Placentophagia in humans and nonhuman mammals: causes and consequences. Ecol. Food. Nutr. 51(3):177-197.

Lucena R.B., Giaretta P.R., Tessele B., Fighera R.A., Kommers G.D., Irigoyen L.F. \& Barros C.S.L. 2012. Doenças de chinchilas (Chinchilla lanigera). Pesq. Vet. Bras. 32(6):529-535.

Macfaddin J.F. 2000. Biochemical Tests for Identification of Medical Bacterial. 3rd ed. Lawrence McGrew, Lippincott Williams and Wilkins, Philadelphia. 901p.

Martinez A.C., Oliveira F.S., Abreu C.O., Martins L.L., Pauloni A.P. \& Moreira N. 2013. Colheita de sêmen por eletroejaculação em cutia-parda (Dasyprocta azarae). Pesq. Vet. Bras. 33(1):86-88. 
Martins L.L., Oliveira F.S., Machado M.R.F., Maluta R.P., Mendes S.R.C. \& Ávila F.A. 2012. Análise microbiológica do útero e da vagina em cutias nulíparas e não-nulíparas (Dasyprocta azarae). Biotemas 25(4):181-184.

Montanha F.P., Corrêa C.S.S. \& Parra T.C. 2012. Maceração fetal em gata em decorrência do uso de contraceptivos - relato de caso. Rev. Cient. Elet. Med. Vet. 10(19):1-6.

Murray P.R., Baron E.J., Pfaller M.A., Tenover F.C. \& Yolken R.H. 2003. Manual of Clinical Microbiology. 8th ed. ASM Press, Washington, DC, 47(4):625-626.

Nakade U.P., Garg S.K., Sharma A., Choudhury S., Yadav R.S., Gupta K. \& Sood N. 2015. Lead-induced adverse effects on the reproductive system of rats with particular reference to histopathological changes in uterus. Indian J. Pharmacol. 47(1):22-26.

Nascimento E.F. \& Santos R.L. 2003. Patologia da Reprodução dos Animais Domésticos. 2nd ed. Guanabara Koogan, Rio de Janeiro, p.48-69.

Ohashi O., Miranda M.S., Santos S.D., Cordeiro M.S., Costa N.N. \& Silva T.V. 2012. Distúrbios reprodutivos do rebanho bubalino nacional. Ciênc. Anim. 22(1):171-187.

Olinda R.G., Feijó F.M.C., Alves N.D., Amorim R.N.L., Alves H.M., Batista J.S. \& Oliveira M.F. 2010. Otite bacteriana em cateto (Tayassu tajacu Linnaeus, 1758) criado em cativeiro. Acta Vet. Brasilica 4(2):113-117.

Pothmann H., Prunner I., Wagener K., Jaureguiberry M., Sota R.L., Erber R., Aurich C., Ehling-Schulz M. \& Drillich M. 2015. The prevalence of subclinical endometritis and intrauterine infections in repeat breeder cows. Theriogenology 83:1249-1253.
Prophet E.B., Mills B., Arrington J.B. \& Sobin L.H. 1992. Laboratory Methods in Histotechnology. Armed Forces Institute of Pathology, Washington, DC, p.1-279.

Quesnel H., Pasquier A., Mounier A.M. \& Prunier A. 1998. Influence of feed restriction during lactation on gonadotropic hormones and ovarian development in primiparous sows. J. Anim. Sci. 76:856-863.

Rolim Filho S.T., Ribeiro H.F.L, Vale W.G., Picanço N.S., Barbosa E.M, Ferreira R.N. \& Simões A.R. 2011. Involução uterina, atividade ovariana, primeiro cio pós-parto e distúrbios reprodutivos em búfalas. Ciênc. Anim. Bras. 12(2):221-227

Ticianelli J.S., Oliveira B.M.M., Zogno M.A., Arruda R.P. \& Celeghini E.C.C. 2011. Intersexo e outras anomalias do desenvolvimento do aparelho reprodutor nos animais domésticos e o auxílio da citogenética para o diagnóstico. Revta Bras. Reprod. Anim. 35(1):26-32.

Vieira G.G. 2009. Desertificação e convivência com o semiárido brasileiro: da casa de Adobe e do mocó à agroecologia e permacultura na região de Gilbués, Piauí. OKARA: Geografia em Debate 3(1):23-53.

Xu D., Xiong H., Xiao Z., He J., Liao Q., Xue L., Wang N. \& Yang Q. 2015. Uterine Cytokine Profile in a Rat Model of Endometritis. Am. J. Reprod. Immunol 73:214-220.

Wagener K., Grunert T., Prunner I., Ehling-Schulz M. \& Drillich M. 2014. Dynamics of uterine infections with Escherichia coli, Streptococcus uberis and Trueperella pyogenes in post-partum dairy cows and their association with clinical endometritis. Vet. J. 202:527-532. 